\title{
Viable retirement solutions for the long-run: Are there any sustainable retirement solutions out there?
}

\section{J. Richards*, M. Hurd and I. Clacher}

[Presented to the Institute and Faculty of Actuaries: 12 December 2016]

\begin{abstract}
This paper examines the resilience of various retirement solutions in the context of factors that can influence their sustainability. First, by considering the desirable features of retirement solutions within the United Kingdom, the authors outline the key levers available to the architects of retirement vehicles to ensure stability. Second, to measure "resilience" the authors create a failure score to establish a method of determining if a vehicle has "failed". Third and finally, we look at those external forces that influence the likely longevity of a retirement solution.
\end{abstract}

\section{Keywords}

Pensions; Defined Ambition; Sustainability

\section{Introduction}

How individuals will achieve adequate retirement incomes is one of the key policy challenges facing government. With the disappearance of open defined benefit ${ }^{1}$ arrangements in the private sector largely complete, and the seemingly inevitable decline and erosion of these benefits in the public sector, the question of what benefits to provide individuals, and how to structure these benefits, is an issue of fundamental importance. If suitable retirement savings vehicles are not found, and individuals are consigned to inadequate defined contribution schemes, then this has three major consequences. First, it is likely that there will be increasing amounts of pensioner poverty for those future retirees not in the defined benefit generation. Second, from the government's perspective, any large-scale deficiencies in retirement income across the population, in all likelihood, will have to be funded at least in part by the state. Third, capital accumulation across the economy may fall without the incentive to save, thereby removing a significant pool of capital that can be invested in the growth of the UK economy.

In looking to rectify the current situation, one issue that is often ignored in debates about retirement provision is the underlying objective of retirement income. Forgetting what retirement income is meant to achieve, or not being explicit about the goal of retirement saving, can often lead to incorrect comparisons, unclear objectives, or unrealistic goals. We therefore start with the basic economic objective of why individuals would rationally save for their retirement. Simply put, individuals have

*Correspondence to: J. Richards, BBS Consultants \& Actuaries, Canard Court, 23-25 St George's Street, Bristol BS1 5UU, UK. E-mail: jenny.richards@bbs-actuaries.co.uk

1 Throughout this paper we use the term "defined benefit" scheme to refer to a type of traditional final salary scheme, as prevalent in the United Kingdom in recent decades. 
an economic lifecycle, and so in work some portion of current remuneration is deferred and placed into a pension pot so that consumption can be taken in retirement when an individual is no longer economically active (Clacher \& Draper, 2015). Retirement income therefore gives an individual command over future economic resources. The notion of deferring present consumption for future consumption was summed up by Barr and Diamond "People seek to maximize their well-being not at a single point in time, but over time. Someone who saves does not do so because extra consumption today has no value, but because he values consumption in the future more highly than extra consumption today"(2006). This notion of inter-temporal consumption smoothing is the underlying economic basis for our analysis, and so we aim to assess what retirement system best fits this economic objective, subject to constraints such as employer costs, individual risks and so on.

As part of the government's desire to "Reinvigorate Workplace Pensions" (Department for Work and Pensions, 2012) there is an acknowledgement that pure defined contribution pension schemes with low levels of contributions (such as auto enrolment minimum levels) are unlikely to be sufficient to provide retirement incomes at historical levels. At the same time, defined benefit pensions at least in the private sector, are proving too expensive at the current level of target benefits and carry too much risk for employers to provide such an arrangement within current regulation. One consequence of this is the emergence of hybrid ${ }^{2}$ pension schemes such as collective defined contribution or defined benefit variants. Further, the government indicated its interest in supporting something that could fill the gap, between inadequate levels of benefits or overly costly alternatives, with appropriate risk-sharing mechanisms. The exact nature of such arrangements was never fully defined although the government did give them a label: "defined ambition" schemes. Moreover, the government also recognises the need to increase savings rates, as individuals simply do not save enough. Indeed, the government has sought to increase the take-up of workplace pensions with the start of auto-enrolment, which compels individuals to undertake pensions saving, albeit at very low rates.

However, one of the drawbacks of the Government's original consultation on defined ambition was that it identified and asked for comment on specific structures, even though it was intended to spark debate on a wider scale. This acted to constrain the industry and responses were limited to consideration of those structures put forward. We feel a more robust approach is to start from the very core of what a retirement system is trying to achieve and then identify what would cause it to fail to provide what it was intended to provide.

In tackling the problem in this way, we try to achieve two things. First, is not to ascribe a particular preference for any structure from the outset, and second, is to try to develop new insights and ideas. In the words of Keynes (1936), "the difficulty lays not so much in developing new ideas as escaping from old ones" and this is arguably truer for retirement systems than in many other areas of economic policy.

\section{Various Retirement Solutions}

In this and the next two sections, we set out the different types of retirement system that exist within the United Kingdom as well as some of the suggested hybrid and "defined ambition" structures that are being proposed as possible structures for a resilient and sustainable pension solution. First, we look at those generic vehicles that exist and their relative advantages and disadvantages. Second, we specifically assess what arrangements exist in the United Kingdom at the current time.

2 Throughout this paper we use the term "hybrid" scheme to refer to a type of scheme that has both defined benefit and defined contribution characteristics. 


\subsection{Defined contribution}

Where a new scheme is established, the most common retirement system currently offered in the private sector is a defined contribution scheme. The structure of a defined contribution scheme is often perceived as simple. However, complexities around investment choices, contribution choices, and retirement choices are often overlooked. The employee and the employer contribute a fixed percentage of salary to the retirement fund. These contributions are then invested in a portfolio of assets and the final value of the pension fund is the sum of the lifetime contributions paid into the scheme, and any returns on the assets earned over the accumulation period. On retirement, the accumulated pot (contributions and investment returns) has historically been invested in an annuity that pays a set level of income for the rest of that individual's life. It is noted that the removal of the requirement to invest in an annuity with retirement savings has allowed a number of other options with retirement income.

Defined contribution arrangements, however, are considered inadequate in many cases, and employers recognise that these pensions provide poor outcomes for employees compared to more generous defined benefit schemes (The Association of Consulting Actuaries, 2013). That said, significantly better outcomes can be achieved for employees if contribution levels are higher than current norms and economic conditions prove favourable. A typical defined contribution arrangement absolves employers from any financial retirement risk, and eliminates any notion that a pension is a risk-sharing agreement between the employee and the employer. As a result, individuals are left to bear investment risk, inflation risk, interest rate risk, and longevity risk. Moreover, individuals are expected to make investment decisions that they rarely have the relevant knowledge and understanding to undertake. Further, where individuals do not make a choice, they end up in default funds, which may not be suitable for them (Byrne et al., 2007).

\subsection{Defined benefit}

A final salary defined benefit pension is often perceived as the most generous form of pension, especially when the historical levels of benefits provided as defined benefits in the private sector are compared to those offered at the current time under defined contribution schemes with considerably lower contribution levels. It is worth noting that this observation is based on the escalation of historical defined benefit levels due to vesting and indexation and the trend to pay lower levels of contribution into defined contribution arrangements. Here, the retirement income that is paid out is a function of age, years of employment, contributions, and final salary. Similar to a defined contribution retirement system, contributions are paid by the employer and the employee and invested in a portfolio of assets. On retirement, however, the retirement income that retirees will receive is a function of pension accrual and not the value of their "own" pension pot. A typical example for the United Kingdom is a $1 / 80$ basis. For each year of employment, an individual accrues $1 / 80$ of her final salary. If an individual stays with the same employer and has a working life commencing at age 25 and retirement at age 65 , the individual accumulates 40 years of pensionable service - meaning she will be eligible to receive $40 / 80$, or $50 \%$, of her final salary as a pension.

Such an arrangement can be viewed as an upper limit of target pensions, as it places all of the risk on the employer, and so the employee essentially only pays their contribution and takes minimal risk via the employer reneging on the retirement promise. Moreover, from the perspective of the employer, this type of arrangement is now a binding debt because of successive legislative changes. Rightly or wrongly, the result of this is there are now few pure defined benefit pension scheme 
arrangements in the private sector that are open to new members. Indeed, the Pensions Regulator Purple Book 2015 shows that only 13\% of schemes are open to new members.

\subsection{Cash balance schemes}

A cash balance scheme is a risk-sharing scheme in which an employer provides some assurances regarding a retirement savings "retirement pot" that will be made available to scheme members at normal pension age. Generally, the employer pays a percentage of salary each year into the scheme. This can be indexed to protect accruals from inflation and, in addition, benefit from a discretionary notional "investment" return. One of the features of such as scheme is that the employer takes on pre-retirement investment risk, while the member takes on the longevity and interest rate risk at retirement. The differentiating factor in a cash balance scheme, compared with a defined contribution scheme is that the employer still has to fund a certain level of benefit, although not to the extent of a pure defined benefit retirement income. As a result, the revaluation of the account does not depend on market conditions alone, and is subject to some kind of assurance.

\subsection{Career average revalued earnings}

Career Average Revalued Earnings are a type of defined benefit arrangement and so the pension received is dependent on pensionable service, career average earnings adjusted (usually for inflation) and the accrual rate of the scheme, for example, 1/80. As with most retirement systems, employee and employer contributions are invested in a fund, and that fund is then used to pay a retirement income. However, here there are still risks on the employer-side post-retirement as the benefit remains defined, although it is not usually to the same level as pure defined benefit (depending on the level of benefit and nature of the membership). However, there are different complexities that exist in this system such as the choice of the correct measure of inflation to index salaries by, for example, Retail Price Inflation or Consumer Price Inflation. Moreover, there will be situations where pension increases outpace wage growth, for example, in the public sector there has been a $1 \%$ salary cap in place for 5 years. Alternatively, if the salary indexation were linked to the average wage growth, then for an individual whose salary increases are below the average this would result in members receiving higher benefits under this type of arrangement than in a final salary scheme.

\subsection{Collective defined contributions}

Collective defined contribution plans are similar to pure defined contribution plans. Employers and employees contribute a fixed percentage of salary into a pension fund and these contributions are invested over the life of the employee. These contributions and investment returns accumulate to a terminal pot, which is then used to finance retirement income. Where a collective scheme differs from a pure defined contribution scheme, is that the money is pooled and members accrue a nominal retirement income without a specific pot of money or account. Moreover, these schemes target a specific level of benefits, but unlike in a defined benefit scheme this is not a promise but an endeavour. For example, pension accrual and indexation is dependent on fund performance and as a result, indexation can be reduced where the fund performance has fallen below expectations. Such a structure has a number of benefits. First, it is viewed as a defined contribution arrangement, and so from a company perspective, this is much easier to deal with in terms of corporate accounts, as it does not have the impact on the balance sheet or regular adjustments to the income statement of the sponsor that a defined benefit scheme has. Second, from an individual's point of view, investment decisions are made on an aggregate basis and do not rely on an arbitrary investment choice at the age of 25 that will have a significant 
bearing on pension wealth. However, this approach is not without issue. In particular, the nature of risk sharing needs to be defined and how such funds should be regulated going forward is something of an open question.

\section{Current Political and Regulatory Landscape}

\subsection{The decline of defined benefit pensions}

The decline of the defined benefit pension scheme is a topic that has been discussed for over 20 years. There are multitudes of factors that explain why defined benefit pensions are all but dead in the private sector. To understand some of the issues requires an historical perspective. When defined benefit pensions were first introduced they were a "best efforts" type arrangement. For some level of contribution, some level of benefits would be provided based upon final salary and some notion of what was affordable.

At the time when many private sector defined benefit pension schemes were established in the 1970s and 1980s, prevailing interest rates were considerably higher than at the current time. Indeed, from 1972 to 1992 , bank rates were often in excess of $8 \%$ per annum, except for one short period. Given that pension scheme affordability is often assessed by reference to future investment returns, the lower interest rate environment has severely challenged the sustainability of schemes that originally assumed much higher future investment returns.

In addition, in the period since these schemes were established, there has been the progressive hardening of this promise changing it from a "best efforts" type arrangement to a binding debt on the employer. Coupled with this, there has been a dramatic increase in life expectancy and so employers were facing an uncapped and binding debt, and when viewed in this way, such an obligation presents a real and tangible risk to the sponsor.

Since the 1970s, successive governments have also changed the tax and regulatory landscape, and the cumulative effect of incremental changes and discrete regulatory responses have had a catastrophic effect on the funding and affordability of defined benefit pension schemes. Some of the more significant changes have included capping scheme funding in the mid $1980 \mathrm{~s}$ at $105 \%$ of a statutory test, which lead to sponsors taking contribution holidays to adjust the asset profile or increasing benefits to increase liabilities. In 1997, the tax relief on dividends was abolished, which reduced the cash flows of schemes. Latterly and probably most controversially, was the move away from traditional actuarial models to a financial economics approach and mark-to-market accounting. While the debates around the rights and wrongs of this still abound, it cannot be denied that it has changed the nature of the obligation and as a result has contributed to the decline, and ultimate death, of the traditional defined benefit pension.

\subsection{Why defined contribution is going to fail}

The idea that defined contribution can fail seems odd. It is a cash balance scheme without assurances and what an individual has at the end provides that individual with a retirement pot. However, the levels of contributions into new defined contribution schemes are often very low compared with the contribution rates for defined benefit. As a result, there has been a large drop in savings rates relative to those observed when defined benefit pensions were commonplace. Moreover, for many, the retirement income being generated by lower cost defined contribution systems is inferior to defined 
benefit schemes. There are two consequences. First, individuals will not be able to retire when they want to on a pension they view as adequate. Second, the perception of the defined contribution retirement system as the very poor relation of the defined benefit retirement system means that individuals will not engage with retirement savings.

More recently, defined contribution pensions have received negative press. If contributions matter in defined contribution outcomes, then costs clearly matter as well. There are an increasing number of stories ${ }^{3}$ that report defined contribution funds as too costly to generate anything like the returns required, and many of these are based on false comparisons. If individuals believe that they are being "ripped-off" by the industry, then individuals will not engage with retirement savings, and even in the auto-enrolment environment, they will do so in a minimal way.

Combined with this lack of engagement, employers are now looking at the defined contribution system as being inadequate, in as much as it does not add to a good model to recruit, reward, and retain. A defined benefit retirement system gave employers some hold on talent and some loyalty built up between employer and employee. However, this does not exist in a defined contribution system, so the inadequate retirement incomes have long-term implications for talent management.

In summary, low-quality uncertain outcomes, low savings and engagement rates, bad press, and longer-term workforce concerns means that the defined contribution system, at least in its current form, is going to fail in a number of different aspects. Ultimately, while these schemes work on a mechanical basis, the resultant low level of engagement and potential for insufficient retirement outcomes means that such scheme fail.

\section{Five Pillar Retirement Saving and the Relative Need for Sustainability}

We will outline the present arrangements in order to set the context for our arguments. First, the state pension creates a foundation on which private retirement income should build. Second, we create the boundaries in which retirement income can operate, that is to say the extremes of the distributions, with defined contribution (at low contribution levels) at one end of the spectrum and defined benefit (with generous target levels of benefits) at the other. Both of these models through time have removed a crucial lever in the ability to flex retirement savings, namely, that of pensions being a best endeavours risk-sharing agreement. It is therefore sensible for the options that lie between these two extremes to be the focus of current policy debates, and the core of building up what structures seem to best able to allow for the development of a fair and sustainable retirement system.

In the United Kingdom there are five pillars to retirement saving. It is important to set out clearly the different sources of possible pension income that an individual could expect to utilise in their retirement. Moreover, the different dimensions of these sources come with very different risks to the individual. For example, younger higher earners run a significant political risk that they will not receive their full state pension. Moreover, when it comes to private pension savings, it is likely that the government will continue to erode the value of the pension benefits, whether in defined benefit or defined contribution, via reductions in the annual allowance and the lifetime allowance. By setting out these various pillars and their concomitant "risks", we can contextualise the broader pension

${ }_{3}$ There are numerous references available, but many are recorded in the popular press. 
savings environment that a "new" collective pensions vehicle will have to be effective in. The five pillars of retirement saving are as follows:

Pillar 1: State pension, which from 2016 is broadly a flat rate pension, which is payable to all qualifying individuals and at the time of writing, this amounts to a maximum of $£ 155.65$ per week. In addition, some individuals will receive a higher overall state pension through the State Second Pension, known as SERPS, which applied for the period 1978-2016.

Pillar 2: Auto-enrolment pension, the pension that is provided from the minimum contribution requirements under the UK auto-enrolment legislation. Individuals can opt out of pillar 2 retirement saving if they choose to do so. This pillar is motivated and defined by government and in many instances, the observed contribution rates are at the minimal levels allowed under current legislation.

Pillar 3: Work place retirement savings in qualifying vehicles provided by employers, where contributions are typically paid by both employers and individuals towards providing a pension at retirement. Here workplace retirement savings are set apart from automatic enrolment as many employers offer pensions outside of governmental compulsion to do so and in many instances this will go beyond the minimal contribution levels that are emerging in the automatic enrolment market.

Pillar 4: Personal retirement savings, which are retirement savings secured by an individual as part of their financial planning for retirement. These contributions may be through additional voluntary contributions to a workplace arrangement, or to a separate private retirement fund.

Pillar 5: Individual non-retirement savings, which are other assets that are available at retirement to the individual that were not intended as retirement savings.

Individuals differ in their retirement needs. Key determinants of their retirement requirements are age and earnings. By considering nine classes of individuals, we can assess the relative merits of retirement savings features and how they inter-link.

\subsection{Pillar 1 retirement savings: flat rate state pension}

The first pillar of an individual's retirement income in the United Kingdom is the state pension. This has recently been reformed and from the 6 April 2016 the maximum amount that individuals will receive from the single-tier state pension will be $£ 155.65$, assuming that an individual has 35 years of national insurance contributions (or credits). In addition, some individuals will receive a higher overall state pension through the State Second Pension, known as SERPS, which applied for the period 1978-2016. Moreover, the current government has committed in its manifesto to the pensions "triple lock" and so increases in benefits will be the higher of the previous year's increase in average earnings, price inflation or $2.5 \%$.

There is already considerable literature regarding how the current system of combined private and public provision has evolved, such as the comprehensive summary of the background of UK pensions provided by the Institute for Fiscal Studies paper "A history of state pensions in the UK: 1948 to 2010" (2010). In order to provide a context, we have summarised the more recent developments, including commentary on those features that appear to have led to inherent instability. It is clear, however, that the intended purpose of the these various state systems has varied significantly depending on economic and political 
sentiment of the time. Whilst it is of interest contextually, in order to assess the fundamental sustainability of retirement systems, the specifics of the current state provision are not considered in detail.

One way of viewing the state pension is income redistribution via taxation. Redistribution is an objective of most tax systems, and in particular, systems of income tax. Underpinning this approach are notions of fairness, equity, and proportionality, whereby those on higher incomes pay more in tax relative to those on lower incomes. This principle is consistent with one of Adam Smith's canons of an ideal tax. Individuals earning more pay greater amounts of tax over their working life and receive a pension that is lower relative to how much they have paid, while those on low incomes receive a more generous pension relative to their contributions via national insurance in this case.

For analysing this pillar, we consider the replacement ratio across income and age. While this is not a perfect yardstick, it does allow for some useful decomposition of an intrinsically complex problem.

In particular, for the purposes of the analysis below we are looking at individuals in large income bands and considering general patterns, rather than specific outcomes. We consider the various pillars to ascertain if there is a particular cohort where the efforts of sustainable retirement vehicles should be focussed. In doing so, we can draw high-level conclusions, which can inform both the direction and implications of our subsequent analysis.

In order to use this metric, which is the ratio of earnings in the years immediately pre- and postretirement, we need be clear about what we mean by earnings. For this purpose, earnings should be taken to be those earnings that will cease on retirement, that is, those that we are seeking to replace with the various forms of post-retirement income.

Table 1 sets out the results of this approach for the flat rate state pension. The results show that for low earners, the levels of benefit intended to be provided by pillar 1 retirement benefits are likely to be sufficient to provide reasonable replacement ratios for these individuals, albeit that the levels of pre-retirement income for these individuals might be considered to be inadequate in itself.

The results also highlight the significant political risk of pillar 1 retirement savings for younger individuals. Historically, the accrued benefits of pensioners have been insulated from the effects of political change in the United Kingdom. This applies for both changes to state pension provision or government imposed changes to private provision. First, existing pensioners have a lower ability to make good any unexpected shortfalls. These individuals are, typically, in the net consumption part of their life cycle and have fewer alternative sources of income. Second, pensioners have significant political influence. It is notable that during times of economic downturn, for example, the credit crunch of 2008, pensioners were one of the few sections of the population that were not subject to cuts. Younger individuals, however, are subject to much higher levels of political risk, whereby future governments may change future benefits to be provided by the state in retirement. Indeed, there is considerable discussion regarding the possibility of means-testing future state pensions. The impact of removing or reducing this benefit would be that higher earners would need to replace this lost income through alternative means (pillars 4 and 5).

\subsection{Pillar 2: auto-enrolment}

One significant change in the retirement landscape has been the introduction of auto-enrolment. Once auto-enrolment has been fully rolled out, this will result in all employees having access to some form of workplace retirement savings. This is a huge shift in the policy objectives of government as it 
Table 1. Approximate Replacement Ratio by Earnings Band and Age (Based on a Flat Rate State Pension of $£ 8,093$ Per Annum)

\begin{tabular}{|c|c|c|c|}
\hline $\begin{array}{l}\text { Per Annum Earnings } \\
\text { (Before Tax) }\end{array}$ & Age 25 & Age 40 & Age 55 \\
\hline$£ 10,000$ earnings & $\begin{array}{l}81 \% \text { replacement ratio } \\
\text { Likely to be deemed sufficient so as to not be key } \\
\text { focus of cohorts requiring additional post- } \\
\text { retirement income } \\
\text { Long-term political risk that benefit will not } \\
\text { remain at this real level of benefits through } \\
\text { successive downwards adjustments }\end{array}$ & $\begin{array}{l}81 \% \text { replacement ratio } \\
\text { Likely to be deemed sufficient so as to not be key } \\
\text { focus of cohorts requiring additional post- } \\
\text { retirement income } \\
\text { Medium-term political risk that benefit will not } \\
\text { remain at this real level of benefits through } \\
\text { successive downwards adjustments }\end{array}$ & $\begin{array}{l}81 \% \text { replacement ratio } \\
\text { Likely to be deemed sufficient so as to not } \\
\text { be key focus of cohorts requiring } \\
\text { additional post-retirement income }\end{array}$ \\
\hline$£ 30,000$ earnings & $\begin{array}{l}27 \% \text { replacement ratio around half of that } \\
\text { traditionally targeted. So likely to require partial } \\
\text { subsidy from alternative sources } \\
\text { Significant risk that this benefit will become means } \\
\text { tested at this income level by the time they reach } \\
\text { retirement age resulting in a large gearing effect, } \\
\text { potentially doubling the amount they might have } \\
\text { otherwise have had to source from alternative } \\
\text { sources }\end{array}$ & $\begin{array}{l}27 \% \text { replacement ratio around half of that } \\
\text { traditionally targeted. So likely to require partial } \\
\text { subsidy from alternative sources } \\
\text { Significant risk that this benefit will become means } \\
\text { tested at this income level by the time they reach } \\
\text { retirement age resulting in a large gearing effect, } \\
\text { potentially doubling the amount they might have } \\
\text { otherwise have had to source from alternative } \\
\text { sources }\end{array}$ & $\begin{array}{l}27 \% \text { replacement ratio around half of that } \\
\text { traditionally targeted. So likely to } \\
\text { require partial subsidy from alternative } \\
\text { sources }\end{array}$ \\
\hline$£ 100,000$ earnings & $\begin{array}{l}8.1 \% \text { replacement ratio } \\
\text { All post-retirement income can be deemed to need } \\
\text { to be sourced from alternative sources } \\
\text { Significant risk of this income becoming means } \\
\text { testing by retirement age, however, not likely to } \\
\text { be a significant factor given likely low level of } \\
\text { reliance on this pillar }\end{array}$ & $\begin{array}{l}8.1 \% \text { replacement ratio } \\
\text { All post-retirement income can be deemed to need } \\
\text { to be sourced from alternative sources } \\
\text { Moderate risk of this income becoming means } \\
\text { testing by retirement age, however, not likely to } \\
\text { be a significant factor given likely low level of } \\
\text { reliance on this pillar }\end{array}$ & $\begin{array}{l}8.1 \% \text { replacement ratio } \\
\text { All post retirement income can be deemed } \\
\text { to need to be sourced from alternative } \\
\text { sources } \\
\text { Some risk of means testing by retirement } \\
\text { age, however, not likely to be a } \\
\text { significant factor given likely low level of } \\
\text { reliance on this pillar }\end{array}$ \\
\hline
\end{tabular}


Table 2. Approximate Replacement Ratio by Earnings Band and Age Post-Auto-Enrolment (Based on a Flat Rate State Pension of $£ 8,093$ Per Annum)

Per Annum Earnings (Before Tax)

\begin{tabular}{ll}
\hline$£ 10,000$ earnings & $81 \%$ replacement ratio \\
& Likely to be deemed sufficient so as to not be key focus \\
& of cohorts requiring additional post-retirement income \\
$£ 30,000$ earnings & $67 \%$ replacement ratio \\
$£ 100,000$ earnings & $26 \%$ replacement ratio \\
\hline \hline
\end{tabular}

is nudging individuals towards a culture of saving and investing for their retirement. As it stands today, employees who earn over $£ 10,000$ per annum must be auto-enrolled into a retirement savings vehicle; although the minimum current contribution rates are currently just $3 \%$ of qualifying salary, by 2020 this will stand at $8 \%$. When considering what an adequate retirement income might be, this level of contributions is likely to result in an insufficient outcome. However, the move to autoenrolment is a significant cultural shift, as the workforce as a whole will largely be enrolled in some sort of pension saving vehicle.

It is widely reported that current levels of auto-enrolment contributions are for most, not sufficient to deliver sufficient levels of retirement benefits for individuals. It is notable, however, that for low and middle earners, when combined with the flat rate state pension provided as pillar 1, reasonable levels of retirement provision are provided.

Table 2 shows an updated expected replacement ratio including pillar 2 for each of the groups identified earlier. Notably, lower-to-medium earners achieve quite high replacement ratios whereas higher earners are much more reliant on pillars 3, 4 and 5. We have not included any view on the political risk as we are assuming that this is only applicable to pillar 1 . Although there is clearly scope for automatic enrolment legislation to be changed, it is unlikely in the near term that the programme of automatic enrolment will be abandoned.

For the examples below, we have used the current long-term expected contributions under auto-enrolment of $8 \%$ total contributions. In addition, it is assumed that if a member is eligible for auto-enrolment all earnings between $£ 6,000$ and $£ 45,000$ are pensionable, investment returns of $5 \%$, conversion factor of 20 (whether an annuity is in fact bought or not we need an annuity to convert the lump sum into a pension stream and an annuity of 20 allows for the potentially more beneficial ways of achieving this than just annuitizing) and 40 years of contributions under this vehicle.

\subsection{Pillar 3: employer sponsored pension arrangements}

Employer sponsored pension provision has been the bedrock of the UK retirement system for many years. This stems from a paternalism that characterised UK businesses during the $19^{\text {th }}$ and $20^{\text {th }}$ centuries. As this paternalism has diminished, in part driven by the influence of US-driven shareholder dominated corporations, there is an ever-increasing move towards individualism. This has led to the demise of the traditional defined benefit scheme, where the employer bears the primary risks, to defined contribution schemes, where the individual bears the primary risks.

In recent times, the move from defined benefit to defined contribution schemes has also been characterised by lower overall pension contribution rates and opt out from pension savings in general. 
This has had the effect of reducing the expected benefits to be provided from pillar 3 and the policy response of automatic enrolment.

\subsection{Pillar 4: individual pension arrangements}

The shift in culture within the United Kingdom from paternalism to individualism has been mirrored by a shift of benefits provided under pillar 3 to benefits provided in pillar 4. In other words, in order to maintain historical replacement ratios, individuals must take on the responsibility of providing their own retirement benefits.

Given the historical reliance on employers (or the state), this represents a significant mind shift for most individuals within the United Kingdom.

Evidence of individualism in practice regarding retirement savings can be seen in the well-established 401,000, which, as well as contributing towards pillar 3 is also a significant provider of pillar 4 benefits, market in the United States or the Swedish market for pension annuities. In both of these countries, where individualism predominates, individuals have higher financial awareness and so provide for their own (pillar 4) retirement benefits.

\subsection{Pillar 5: individual non-retirement savings}

With increased distrust of retirement savings and the reluctance of individuals to dedicate income for retirement, there is increased reliance on pillar 5 retirement benefits. In other words, individuals are increasingly intent on living off existing assets during retirement. There are two problems with such an arrangement.

First, individuals often underestimate the value of residual assets that are required to fund retirement benefits and under pillar 5 they often do not seek external financial advice in order to help them make financial decisions. For example, individuals often claim that the equity in their houses will provide adequate income for retirement, which is in most cases wrong. The average house price in the United Kingdom is $£ 286,000$, (Table 23 UK House Price Index, 2015) which, assuming it was possible to realise the full value of the property would be unlikely to provide an income much greater than $£ 10,000$ per annum through annuity purchase at current annuity rates.

Given it is unlikely the full value of a main residence will be realised as individuals still need somewhere to live, then the above estimate is overstating the potential income that an individual can derive from their property. Individuals will need to use some of the proceeds to purchase a new house, which is unlikely to be attractive as downsizing is challenging given property prices and opens up the possibility of equity release schemes. Finally, individuals are far more likely to spend non-retirement allocated assets outside of property such as savings and investments. Many will justify early expenditure to send a child to university, buy a new car, or even pay for home refurbishments and holidays.

\subsection{Cross-income subsidies}

Most retirement systems include some mechanism for protecting the less wealthy during retirement. In the event that these individuals are not provided for via private mechanisms and the State is committed to reducing poverty levels, then they would fall back on the State and would need to be provided for by alternative means. These subsidies ensure that the less well paid are protected from 
poverty in retirement and this protection is usually achieved by these members being subsidised by those on middle/higher incomes. It is the middle earners that end up shouldering the majority of income cross subsidies within most retirement systems.

The descriptive analysis above highlights that lower paid individuals achieve higher replacement ratios under the UK pillar system. At the same time, higher paid individuals will tend to have greater pillar 5 (non-retirement savings) to rely upon. The "squeezed middle" faces considerable risk of having insufficient retirement savings. Therefore, this cohort is the key demographic that a new regime of retirement systems should target.

\section{Sustainability}

Having explored the background to existing retirement systems, we now explore those features of retirement systems that contribute to their sustainability. Specifically, we consider those features of a retirement system that increase the likelihood that a system established today will still be around in, say, 50 years, in such a manner that allows members to reasonably plan for their retirement. We note, however, that our notion of sustainability does not imply a $100 \%$ guarantee of income level, but rather that this system will have preserved its structure.

\subsection{Terms of Reference for a Retirement Systems}

The notion of sustainability requires consideration of the role of a retirement system in terms of wealth distribution, risk sharing and risk mitigation.

\subsubsection{Wealth distribution}

A retirement system is a wealth distribution vehicle. Regardless of who finances the system, it is a mechanism for individuals to smooth consumption. The individual re-directs income (whether it is directly from the individual, from government or employers) into a vehicle for use at a later date.

\subsubsection{Risk mitigation}

The traditional model of defined benefit and defined contribution schemes portrays a twodimensional risk-sharing spectrum, whereby all of the risk of a defined benefit scheme is borne by the employer and all of the risk of a defined contribution scheme is borne by individuals. However, focus is also required on how much total risk there is within a system. When designing a retirement benefit system, this dimension of total risk is actually more important than whether the underlying risks are borne by the individual or the employer. The first part of the design should always be to reduce risk in the system as a whole.

\subsubsection{Risk sharing}

The traditional model is oversimplified because employers and members do bear explicit risks with both arrangements, but also because any burden placed one party is likely to either directly or indirectly affect the other party. In particular, an excessive burden on any one party can lead to failure of the system.

This requirement to avoid triggering failure through any particular party seeking to absorb an unequal proportion of the overall risk allows us to consider the relative merits of risk-sharing mechanisms such as 
collectivism. At a simple level, by pooling longevity risk (of a single cohort of members to avoid intergenerational transfer) it allows individual members to share average life expectancy risk of their cohort and therefore eliminate the very large risk that they would face (only really achievable by using an insurance product otherwise) if they were covering only their own longevity risk.

\subsection{Defining sustainability and failure}

We define a sustainable retirement system as being one that minimises the likelihood of failure at any point during its lifetime. For the purposes of modelling, we define failure as being the situation whereby any one of the following occurs at any point during the lifetime of the retirement system:

- the benefits provided to individuals are lower than an acceptable level, which we call the "reasonable benefits test"; or

- the financing of the retirement system requires cash injections that are higher than an acceptable level, which we call the "reasonable contributions test".

These tests can be considered to be those situations whereby the retirement system is no longer fit for purpose, either because the benefits provided are inadequate or the burden placed on any party is unaffordable.

The notion of failure leads to the concept of a failure score. The failure score can be interpreted as the expectation of failure during the lifetime of the retirement system. In particular, it reflects the proportion of future scenarios in which failure occurred.

By its nature, failure has to be tested stochastically and at all points during the lifetime of the retirement system. In particular, it is noted that many scenarios trigger a failure, but would later recover if given adequate time. Our definitions of failure, however, are set at such a level that the parties concerned are unable or unwilling to allow additional time for the system to recover.

We consider this definition to capture the reality of sustainability rather than over-estimate the likelihood of success from a theoretical notion that would never be allowed to continue in practice. We do, however, test the levels at which the reasonable benefits test and reasonable contributions test trigger failure.

\subsection{Types of failure}

In order to more fully assess the nature of failure, we use two key metrics to assess the cause of failure:

- Fluctuation failure score

- Absolute failure score

Over the longer term, retirement systems will often correct themselves in situations whereby unfavourable experience is followed by more favourable experience. However, sponsors and beneficiaries make decisions during this time based on the information they have at each point in time. The scheme may become too expensive in the short-term or be expected to provide inadequate benefits causing the sponsor or beneficiary to disengage from the scheme. As such, we define an "absolute failure" as being one in which the level of benefits and contributions is at a level that is in its own right unacceptable to one of the parties concerned at that point in time. For example, if a benefit level falls below a replacement ratio of $25 \%$, say, then the member will no longer have confidence that the scheme will provide for their needs. 
By contrast, a "fluctuation failure" is one in which, the annual variation of contribution required or benefit provided is deemed unacceptable to one of the parties. For example, a benefit with a replacement ratio falling from $60 \%$ to $40 \%$. In itself a replacement ratio of $40 \%$ might not be considered too low, however, a $33 \%$ drop in income from the previous year is likely to cause difficulties for all but the very wealthiest individuals.

These two metrics are applied to both the income and outflow of the scheme, the contributions test and the benefits test. The contributions test could be further extended to different stakeholders if those stakeholders had differing levels of ability to withstand adverse experience. In addition, the analysis could be further extended to allow for individual-specific circumstance at varying points of the individual's lifecycle.

\subsection{Levers to generate sustainability}

Once a retirement system is established, one of the key features of sustainability is the ability of the retirement system to adjust to current circumstances. We analyse these correction mechanisms by considering primary and secondary levers.

\subsubsection{Primary levers}

We use the term "primary levers" to describe the modification of contributions into the retirement system or the benefits provided from the retirement system.

\subsubsection{Secondary levers}

Following on from identifying two primary levers (adjustments to contributions and benefits), we consider "secondary levers", which are those features of retirement system design that cannot be used to restore the system immediately but do impact overall outcomes. Secondary levers include:

1. How quickly any favourable or unfavourable experience is remedied through contributions. This is usually expressed as a period of years.

2. How prudently the retirement system is assessed with regard to whether or not it is likely to achieve its objectives.

3. The investment strategy adopted by the retirement system.

Each of these secondary levers is tested in isolation to the primary levers to isolate the impact that secondary levers have to promote sustainability. In practice, most retirement systems will use a combination of primary and secondary levers to adjust for actual experience.

Although we do not explicitly address this concern, we note that many retirement systems often apply an asymmetric approach to applying primary and secondary levers to remedy favourable and unfavourable experience. In particular, unfavourable experience (often referred to as a deficit) is often considered in a different light to favourable experience (often referred to as a surplus).

\subsection{Regulatory and political influences}

Theoretical solutions will undoubtedly be restricted by regulatory and political constraints. For example, the European case law principles of retroactivity and the protection of accrued rights limit the ability of a retirement system to modify past benefits deemed to have been awarded under a 
retirement system. If adjustments are made to a retirement design then the revised solution should be tested for expected future failure.

To illustrate the need for iterative consideration, we reflect upon the example of introducing compulsory indexation of pensions to the current UK retirement system. The UK Government stipulated that all benefits earned within the system must be revalued at least in line with inflation, subject to a cap of 5\% per annum, from April 1997.

At the time, inflation was eroding the real value of the benefits provided to beneficiaries and the real value of the benefits was so low that the retirement system was in danger of failing a "reasonable benefits test". The change that was introduced, however, may not have been optimal as it ultimately led to failure under the "reasonable contributions test". The paradox of failing one of the two tests partially due to measures introduced to avoid failing the other test is clear. We further assert that the changes made were likely to lead to such a failure at some point in the future and could have been avoided.

\section{Construction of the Model}

In order to test the resilience of various retirement systems, a simplified model of various retirement systems is constructed to test their ability to withstand future experience, as simulated using a stochastic financial model of the future. From this model, we test the retirement systems using the failure measures defined earlier.

The model projects forwards assets and liabilities, 1 year at a time, allowing for economic experience generated by the Economic Scenario Generator. The key variables generated are inflation and asset experience, which includes generating assumptions for future experience to value the liabilities. Each year a "valuation" is carried out to determine the funding level of the scheme and, depending on the parameters being tested, either benefits, contribution levels, or both are adjusted to target "correction" of the funding level.

\subsection{Structure of retirement systems}

We have expressed contributions and benefits into and out of each retirement system as a percentage of notional remuneration. Prior to retirement, this remuneration can be considered to be employment remuneration (or a proxy thereof for non-workers), which is projected in real terms post-retirement to maintain a consistent measure of relative wealth. Remuneration is projected with inflation over the lifetime of the system.

\subsection{Generating economic scenarios}

The nature of the modelling is not to predict member outcomes but rather to explore how these outcomes are affected by various levers. As such, the economic scenario generator does not need to be overly sophisticated, so we have used a simple uncorrelated lognormal distribution for each key variable. The key driver of the economic scenario generator is to replicate volatility in actual experience to test the sustainability of retirement systems.

The economic scenario generator is a simple form auto regressive model developed by the authors that models inflation and invested assets. Further details are included in the Appendix. 
In order to test the validity of this simplification, we also tested one of the basic retirement systems through a more sophisticated model that allowed for correlations and mean-reversion of certain variables. The analysis is included in the Appendix and shows that the introduction of a more complex model does not change our conclusions.

Each retirement system is tested using the same fixed set of 1,000 randomly generated simulations from the economic scenario generator. This approach allows comparability between different retirement systems. Other sets of simulations were also tested to ensure that a different set of simulations would not affect our conclusions. Indeed, whilst some of the results would be slightly different, there would be no change in the magnitude of the failure scores or the conclusions reached.

\subsection{Choice of parameters}

Each variable is assigned both a mean and volatility parameter, as defined in the Appendix. The mean parameter is less important than the volatility parameter, because its impact is to scale the cash flows of the retirement system.

The variance parameter, however, impacts both the necessity for various levers and their effectiveness. As the volatility parameter is a critical determinant of the likelihood of future failure, we have tested all retirement systems in both a "low volatility" and a "high volatility" environment. Future research in this area would benefit from considering a regime switching environment, where there are periods of low volatility and periods of high volatility.

Given the stochastic nature of our projections, we have included summary statistics for each of the key variables under each of the four core sets of simulations that were generated using the economic scenario generator (Table 3).

\subsection{Collectivism versus individuality}

The ability or otherwise for individuals to pool their experience can have a significant impact on the "fairness" of the system, perceived or otherwise. We were therefore keen to test whether the ability to pool experience affected the likelihood of its success when considered in a likeliness of failure setting. As such, we have tested two types of retirement system. Under both retirement systems, the cohort of individuals and the economic scenarios are the same. The individual model, however, applies the contribution test and the benefits test at an individual level, whereas the collective model applies the tests against the retirement system as a whole.

\subsection{Members}

For the purposes of this analysis, we test the outcomes for a group of individuals, all of whom are "average". Future research would benefit from considering a wider variety of individuals and their ability to withstand failure under different retirement systems. Whilst we have not modelled the impact of various retirement systems on different social groups, we note from our earlier discussion that the current UK retirement system provides a minimum level of benefit through the first pillar (state pension) to ensure that higher replacement ratios are provided to those individuals with the lowest incomes.

In defining these "average" members, we have assumed that each individual starts the retirement system expecting to spend 30 years prior to retirement during which he or she pays $15 \%$ of 
Table 3. Results of Parameters Relating to Core Economic Scenario Setups

\begin{tabular}{|c|c|c|c|c|c|c|c|c|c|c|c|c|c|c|c|c|}
\hline & $\begin{array}{l}\text { Long-Term } \\
\text { Assumption } \\
(\%)\end{array}$ & $\begin{array}{c}\text { Annual } \\
\text { Experience } \\
(\%)\end{array}$ & $\begin{array}{c}\text { Long-Term } \\
\text { Real } \\
\text { Assumption } \\
(\%)\end{array}$ & $\begin{array}{c}\text { Annual } \\
\text { Experience } \\
(\%)\end{array}$ & $\begin{array}{l}\text { Long-Term } \\
\text { Assumption } \\
(\%)\end{array}$ & $\begin{array}{c}\text { Annual } \\
\text { Experience } \\
(\%)\end{array}$ & $\begin{array}{c}\text { Long-Term } \\
\text { Real } \\
\text { Assumption } \\
(\%)\end{array}$ & $\begin{array}{c}\text { Annual } \\
\text { Experience } \\
(\%)\end{array}$ & $\begin{array}{c}\text { Long-Term } \\
\text { Assumption } \\
(\%)\end{array}$ & $\begin{array}{c}\text { Annual } \\
\text { Experience } \\
(\%)\end{array}$ & $\begin{array}{l}\text { Long-Term } \\
\text { Real } \\
\text { Assumption } \\
(\%)\end{array}$ & $\begin{array}{c}\text { Annual } \\
\text { Experience } \\
(\%)\end{array}$ & $\begin{array}{c}\text { Long-Term } \\
\text { Assumption } \\
(\%)\end{array}$ & $\begin{array}{c}\text { Annual } \\
\text { Experience } \\
(\%)\end{array}$ & $\begin{array}{l}\text { Long-Term } \\
\text { Real } \\
\text { Assumption } \\
(\%)\end{array}$ & $\begin{array}{c}\text { Annual } \\
\text { Experience } \\
(\%)\end{array}$ \\
\hline Low vol & & & & & & & & & & & & & & & & \\
\hline $\begin{array}{l}\text { Minimum } \\
\text { Maximum }\end{array}$ & $\begin{array}{l}2.8 \\
3.2\end{array}$ & $\begin{array}{l}2.8 \\
3.1\end{array}$ & $\begin{array}{l}3.2 \\
3.7\end{array}$ & $\begin{array}{r}1.5 \\
14.9\end{array}$ & $\begin{array}{l}0.3 \\
0.5\end{array}$ & $\begin{array}{l}0.3 \\
0.5\end{array}$ & $\begin{array}{l}0.4 \\
0.8\end{array}$ & $\begin{array}{l}11.3 \\
19.5\end{array}$ & $\begin{array}{l}1.0 \\
2.5\end{array}$ & $\begin{array}{l}1.2 \\
2.5\end{array}$ & $\begin{array}{l}0.9 \\
2.7\end{array}$ & $\begin{array}{l}-611.0 \\
-11.5\end{array}$ & $\begin{array}{l}3.5 \\
5.0\end{array}$ & $\begin{array}{l}3.5 \\
4.8\end{array}$ & $\begin{array}{l}4.2 \\
6.1\end{array}$ & $\begin{array}{l}26.6 \\
77.6\end{array}$ \\
\hline Mean & 3.0 & 3.0 & 3.5 & 8.0 & 0.4 & 0.4 & 0.6 & 15.0 & 2.0 & 2.0 & 2.1 & -28.7 & 4.0 & 4.0 & 4.9 & 44.3 \\
\hline $\begin{array}{l}\text { High volatility } \\
\text { Minimum }\end{array}$ & & & 3.0 & & & & & & & & & & & & & \\
\hline $\begin{array}{l}\text { Minımum } \\
\text { Maximum }\end{array}$ & 3.3 & 3.3 & 4.0 & $\begin{array}{l}-1.0 \\
16.8\end{array}$ & 1.1 & $\begin{array}{l}.0 \\
1.0\end{array}$ & $\begin{array}{l}.0 \\
1.5\end{array}$ & & 2.0 & 2.0 & $\begin{array}{r}-1.0 \\
2.1\end{array}$ & $\begin{array}{l}-10.0 \\
-23.2\end{array}$ & $\begin{array}{l}.1 .1 \\
6.5\end{array}$ & $\begin{array}{l}3.0 \\
65\end{array}$ & $\begin{array}{l}9.3 \\
94\end{array}$ & $\begin{array}{r}56.3 \\
132.3\end{array}$ \\
\hline Mean & 3.0 & 3.0 & 3.5 & 8.1 & 0.8 & 0.8 & 1.1 & 24.9 & 1.1 & 1.1 & 0.7 & -52.6 & 4.9 & 4.9 & 6.2 & 68.7 \\
\hline
\end{tabular}


remuneration into the retirement vehicle. The individual then expects to spend 20 years in postretirement phase drawing income from the retirement system. Given the focus of this paper on sustainability rather than levels of outcome, the chosen parameters do not influence either the results or the conclusions.

One particular element of the membership model is that demographic assumptions are deterministic. Any increase or reduction in life expectancy during the lifetime of retirement system is ignored. To the extent that fluctuations in this expectation lead to volatility, we can consider the financial assumptions to provide sufficient volatility to simulate this risk. Similarly, the financial assumptions provide sufficient likelihood of an individual "running out of retirement savings" to avoid having to generate dynamic demographic assumptions.

\subsection{Secondary levers}

There are a number of secondary levers that have been tested to assess sustainability.

\subsubsection{Prudence}

One of the secondary levers is whether or not to allow for prudence when making regular assessments of the financial position of the retirement vehicle. For the purposes of this paper, we have tested one margin for prudence, being to assume that expected future returns are $75 \%$ of best estimate expected future returns. Future research could consider varying degrees of prudence and the corresponding impact on failure scores.

\subsubsection{Core parameters}

For some systems, there is a corridor before which surpluses or deficits are available for distribution or remediation. In the system above, an adjustment to benefits, contributions or both occurs in every year that the funding level is not exactly $100 \%$. However, we have also tested systems where the funding level would have to be outside of a specified corridor before contributions or benefits are varied (Tables 4 and 5).

This set of parameters reflects a system where, any surplus or deficit available for redistribution (dictated by the parameters in Table 4 and in this scenario is all of it) is allocated such that $50 \%$ will result in a benefit change with no change to contributions. For example, a funding level of $110 \%$ would result in $5 \%$ being used to increase benefits with contributions remaining at the same level (Table 6).

This set of parameters reflects a system where, any surplus or deficit available for redistribution (dictated by the parameters in Table 4 and in this scenario is all of it) is allocated such that there are no benefit changes and $20 \%$ is used to change contributions. For example, a funding level of $110 \%$ would result in $2 \%$ being used to reduce contributions, for the next year only, and benefits remain at the same level (Table 7).

This set of parameters reflects a system where, any surplus or deficit available for redistribution (dictated by the parameters in Table 4 and in this scenario is all of it) is allocated such that $50 \%$ is used for benefit improvements if the member is at or after retirement and $20 \%$ is used for 1-year contribution reduction if the member is pre-retirement.

Where there is a deficit $20 \%$ will be paid over the next year by an increase in contributions, regardless of the part of the member's lifecycle in which it occurs (Table 8). 
Table 4. Core Parameters for Funding Strategy

\begin{tabular}{lcccccccc}
\hline \hline & \multicolumn{4}{c}{ Surplus } & & & Deficit \\
\cline { 2 - 3 } \cline { 5 - 7 } & $\begin{array}{c}\text { Pre- } \\
\text { Retirement }\end{array}$ & $\begin{array}{c}\text { In Year of } \\
\text { Retirement }\end{array}$ & $\begin{array}{c}\text { Post- } \\
\text { Retirement }\end{array}$ & $\begin{array}{c}\text { Pre- } \\
\text { Retirement }\end{array}$ & $\begin{array}{c}\text { In Year of } \\
\text { Retirement }\end{array}$ & $\begin{array}{c}\text { Post- } \\
\text { Retirement }\end{array}$ \\
\hline $\begin{array}{c}\% \text { of surplus/deficit to reach } \\
\text { before any sharing occurs }\end{array}$ & 100 & 100 & 100 & 100 & 100 & 100 \\
\hline \hline
\end{tabular}

Table 5. Core Parameters for Where Benefits Only are Adjusted

\begin{tabular}{|c|c|c|c|c|c|c|}
\hline & \multicolumn{3}{|c|}{ Surplus } & \multicolumn{3}{|c|}{ Deficit } \\
\hline & $\begin{array}{l}\text { Pre- } \\
\text { Retirement }\end{array}$ & $\begin{array}{l}\text { In Year of } \\
\text { Retirement }\end{array}$ & $\begin{array}{l}\text { Post- } \\
\text { Retirement }\end{array}$ & $\begin{array}{l}\text { Pre- } \\
\text { Retirement }\end{array}$ & $\begin{array}{l}\text { In Year of } \\
\text { Retirement }\end{array}$ & $\begin{array}{l}\text { Post- } \\
\text { Retirement }\end{array}$ \\
\hline $\begin{array}{l}\% \text { of sharable surplus/deficit to result } \\
\text { in permanent change to post- } \\
\text { retirement benefit. Takes } \\
\text { precedence over one off adjustment }\end{array}$ & 50 & 50 & 50 & 50 & 50 & 50 \\
\hline $\begin{array}{l}\% \text { of surplus/deficit required to be } \\
\text { paid off in following year (i.e. conts) }\end{array}$ & 0 & 0 & 0 & 0 & 0 & 0 \\
\hline
\end{tabular}

Table 6. Core Parameters for Where Contributions Only are Adjusted

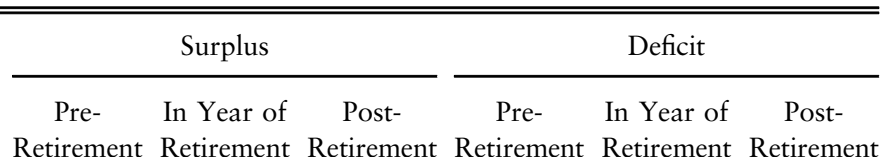

\begin{tabular}{l}
$\begin{array}{l}\text { \% of sharable surplus/deficit to result } \\
\text { in permanent change to post- } \\
\text { retirement benefit. Takes } \\
\begin{array}{l}\text { precedence over one off adjustment } \\
\% \text { of surplus/deficit required to be } \\
\text { paid off in following year (i.e. conts) }\end{array}\end{array}$ 20 \\
\hline \hline
\end{tabular}

Table 7. Core Parameters for Where Both Benefits and Contributions Only are Adjusted

\begin{tabular}{|c|c|c|c|c|c|c|}
\hline & \multicolumn{3}{|c|}{ Surplus } & \multicolumn{3}{|c|}{ Deficit } \\
\hline & $\begin{array}{l}\text { Pre- } \\
\text { Retirement }\end{array}$ & $\begin{array}{l}\text { In Year of } \\
\text { Retirement }\end{array}$ & $\begin{array}{l}\text { Post- } \\
\text { Retirement }\end{array}$ & $\begin{array}{l}\text { Pre- } \\
\text { Retirement }\end{array}$ & $\begin{array}{l}\text { In Year of } \\
\text { Retirement }\end{array}$ & $\begin{array}{l}\text { Post- } \\
\text { Retirement }\end{array}$ \\
\hline $\begin{array}{l}\% \text { of sharable surplus/deficit to result } \\
\text { in permanent change to post- } \\
\text { retirement benefit. Takes } \\
\text { precedence over one off adjustment }\end{array}$ & 0 & 50 & 50 & 0 & 0 & 0 \\
\hline $\begin{array}{l}\% \text { of surplus/deficit required to be } \\
\text { paid off in following year (i.e. conts) }\end{array}$ & 20 & 0 & 0 & 20 & 20 & 20 \\
\hline
\end{tabular}


Table 8. Core Parameters for Failure Scores

\begin{tabular}{|c|c|c|c|c|c|c|}
\hline & \multicolumn{3}{|c|}{ Absolute } & \multicolumn{3}{|c|}{ Relative } \\
\hline & $\begin{array}{l}\text { Pre- } \\
\text { Retirement } \\
(\%)\end{array}$ & $\begin{array}{l}\text { In Year of } \\
\text { Retirement } \\
\qquad(\%)\end{array}$ & $\begin{array}{c}\text { Post- } \\
\text { Retirement } \\
(\%)\end{array}$ & $\begin{array}{c}\text { Pre- } \\
\text { Retirement } \\
(\%)\end{array}$ & $\begin{array}{l}\text { In Year of } \\
\text { Retirement } \\
\qquad(\%)\end{array}$ & $\begin{array}{l}\text { Post- } \\
\text { Retirement } \\
\quad(\%)\end{array}$ \\
\hline $\begin{array}{l}\text { Minimum permanent benefit } \\
\text { levels - inclusive of core } \\
\text { retirement benefit }\end{array}$ & 40 & 40 & 40 & 5 & 5 & 5 \\
\hline Maximum contribution levels & 20 & 5 & 5 & 5 & 5 & 5 \\
\hline
\end{tabular}

This set of parameters will result in a failure score being recorded if a member's benefit outgo or predicted outgo falls below a $40 \%$ replacement ratio. In addition, if the annual fluctuation is more than $5 \%$ a failure will be recorded. In addition, a failure score will be recorded if the contributions required exceed $20 \%$ in the period pre-retirement, $5 \%$ post-retirement, or an annual fluctuation of more than $5 \%$.

\section{Results}

In order to demonstrate the outcome of the modelling, we have included both the summary statistics described earlier and a graphical representation of the net cash into and out of the retirement system. The graphical representations demonstrate the inherent volatility in each retirement system. The charts show the percentage of remuneration paid into the retirement system (negative cashflow) and the percentage of remuneration paid out of the retirement system (positive cashflow). The $\mathrm{x}$-axis shows a notional age for the cohort of individuals being tested.

\subsection{Deterministic vehicle (for illustration)}

The Figure 1 shows the expected outcome in a deterministic world for a retirement system. It is included here for illustrative purposes to demonstrate the target outcome and by way of explanation for the charts that follow. It also acts as a comparative vehicle for further analysis.

In a deterministic world, we know the parameters of the model will be borne out in practice with no volatility. In the chart above, a $10 \%$ contribution is paid into the system pre-retirement (before age 65 ). The contribution is sufficient to achieve a replacement ratio of $67 \%$ post-retirement.

A decision is not required as to how you would adjust benefits or contributions to rebalance the funding level, because the system is always on target.

\subsection{Defined benefit}

By contrast, the deterministic model can be compared to a simple traditional defined benefit model. This model has investment market volatility introduced and some simple smoothing mechanisms, as defined earlier (Figure 2).

Figure 2 shows the paths of each of the scenarios from the modelling. Given the traditional defined benefit model is characterised by guaranteed income post-retirement, the volatility shown emerges from contribution adjustments required to return the vehicle to full funding along the parameters 


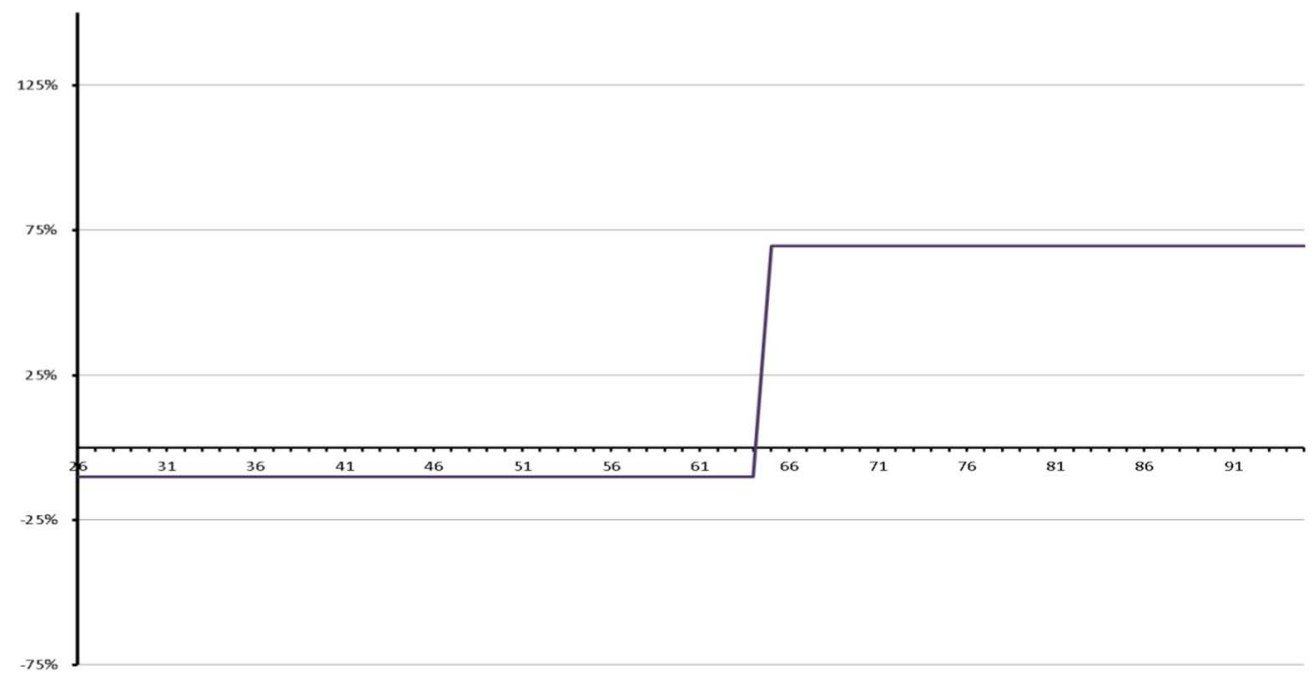

Figure 1. Cashflows for deterministic vehicle

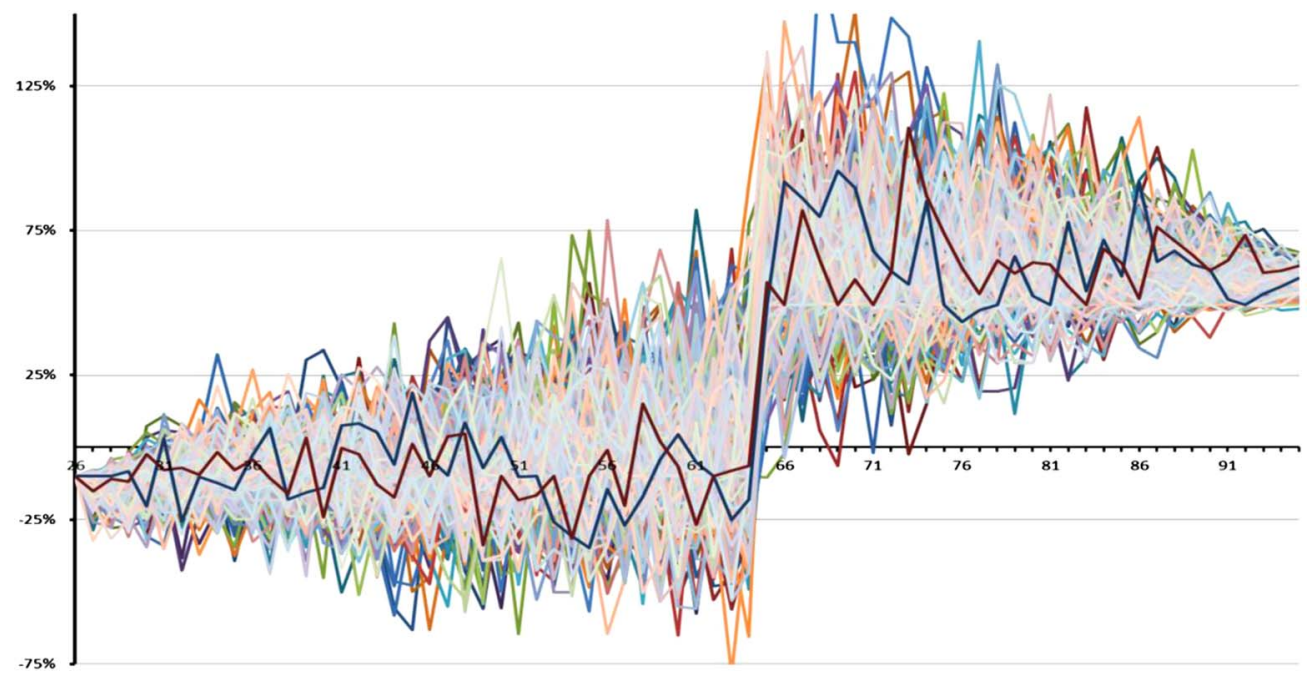

Figure 2. Cashflows for defined benefit vehicle

outlined earlier. In particular, volatility continues post-retirement even once benefits are in payment in those scenarios where additional contributions are required.

It is noted that volatility of each path is evident and, in particular, a number of paths can be seen to cross from unacceptably high contribution requirements (many of which designated as contribution failure) to extremely positive scenarios later in the evolution of the retirement vehicle. Similarly, extremely positive paths can be observed to deteriorate over relatively short periods.

The authors note that such volatility is consistent with those trends observed empirically from existing retirement vehicles in the United Kingdom. 


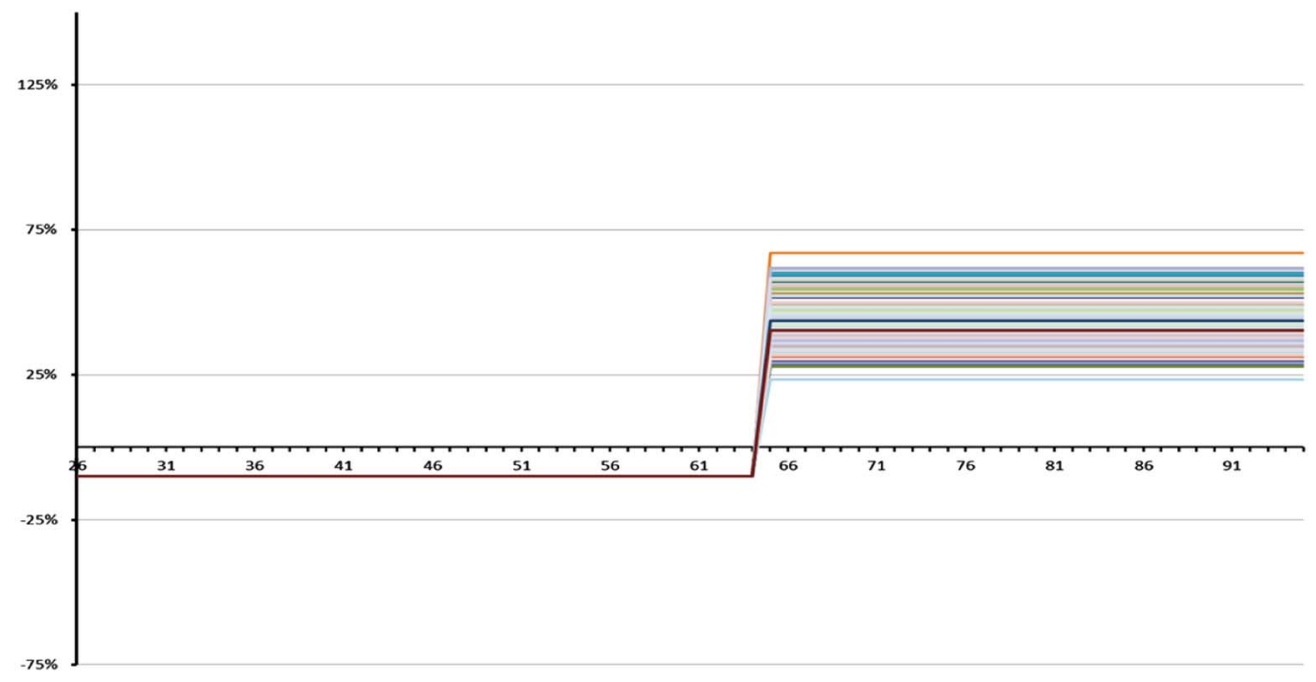

Figure 3. Cashflows for defined contribution vehicle

\subsection{Defined contribution}

The two figures shown previously can now be compared to a traditional defined contribution vehicle, where contributions are fixed in advance and the benefit is guaranteed at retirement through the purchase of an annuity (Figure 3).

It is clearly, observable that a traditional defined contribution vehicle will never fail the contributions test, given that contributions do not fluctuate. Instead the only chance of the vehicle failing is for one cohort of individuals to fail the benefits test. Such scenarios occur where the cumulative investment returns combined with prevailing annuity rates are insufficient to purchase sufficient benefits at retirement.

Given this vehicle must deliver for different cohorts of individuals according to when they enter and retire from the retirement vehicle, the chance of failure is higher than demonstrated in the simplification above.

\subsection{Defined benefit (1980 style: discretionary pension increases)}

To develop the charts shown so far, it is worth expanding upon one particular variant of the defined benefit class of retirement vehicles, namely the 1980s style defined benefit prior to the compulsory indexation of retirement benefits. This particular benefit structure incorporates some of the flexibility that might be considered to increase the likelihood of a defined benefit vehicle avoiding failure (Figure 4).

Whilst the extent of the volatility experienced in contribution levels is very much reduced, the overall picture is very similar to the traditional defined benefit model. The variation of each path between high levels of funding and risk of contribution failure is self-evident.

\subsection{Summary statistics of failures}

The summary statistics show the number of failures, recorded by the model, depending on which primary lever is being adjusted (for both absolute and relative failure) for a traditional defined benefit model with inflation linked benefits. 


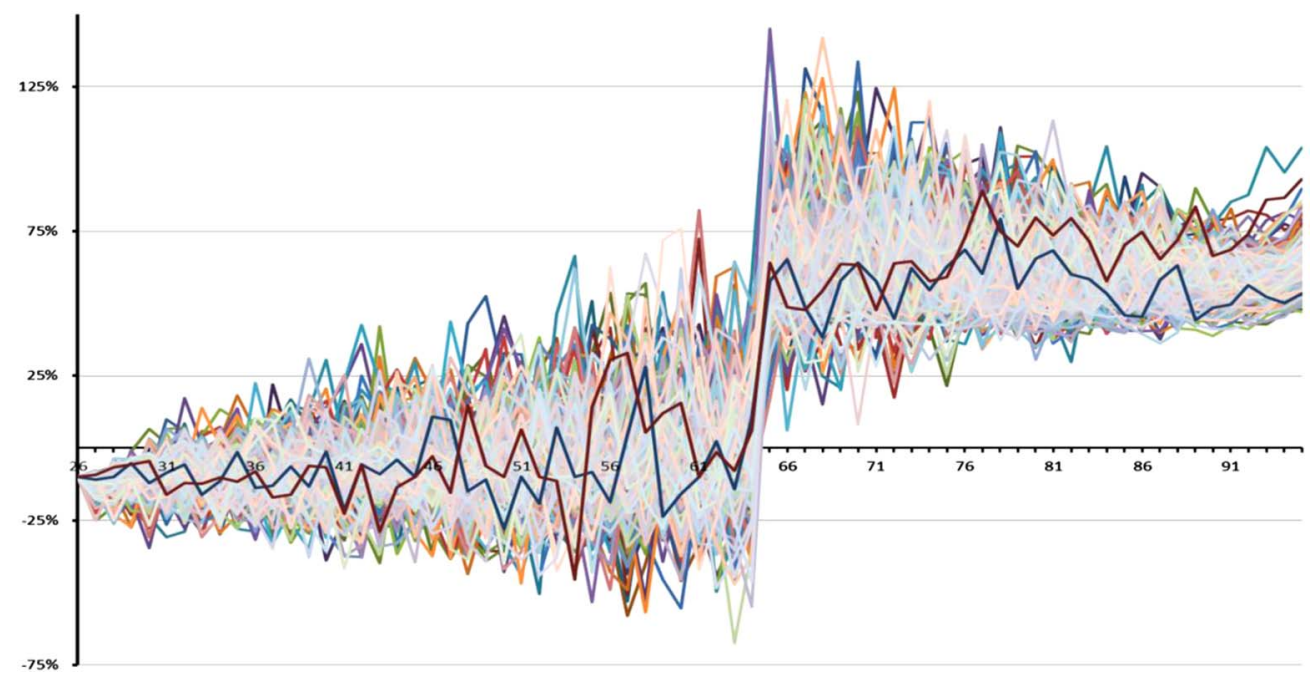

Figure 4. Cashflows for 1980s style vehicle

Each test is carried out for each year the scheme is assumed to be in existence and for each member. The numbers in the table represents the number of times, over all of the economic scenarios, that the scheme breaches a failure parameter. By analysing the changes over alternative parameter scenarios it gives us a powerful tool for exploring inherent weaknesses within retirement savings vehicles and investigate ways in which they be designed out or mitigate as far as possible.

The results set out in Table 9 represents a small subset of the full range of results. Some alternative scenarios are shown in Appendix B and further results are available on request. The conclusions below reflect analysis of the full range of results.

As to be expected, the higher volatility environments are more likely to lead to failure than normal volatility environments. This is particularly concerning, given our earlier remark that in reality periods of high volatility are to be expected for some period during the lifetime of most retirement vehicles.

\section{Model Conclusions}

From the results, it is clear that the traditional defined benefit retirement solution was more likely to fail than not. It is particularly interesting to consider further the features of retirement systems that make them more or less likely to fail.

\subsection{Primary levers}

The ability to adjust primary levers significantly reduces the likelihood of failure. We note, however, that most retirement systems ignore this basic principle and favour certainty of contributions and benefits over increasing the risk of failure.

One of the main drivers to reduce the risk of failure is, unsurprisingly, the ability to smooth adverse experience. At the same time, however, we note the emotive challenges with "unrecognised losses" appearing on assessments of relative funding. Similarly, we note that challenges of maintaining higher 
Table 9. Summary Failure Scores

\begin{tabular}{|c|c|c|c|c|c|c|c|c|}
\hline \multirow[b]{3}{*}{$\begin{array}{l}\text { Primary (Levers } \\
\text { Adjusted) }\end{array}$} & \multicolumn{4}{|c|}{ Normal Volatility } & \multicolumn{4}{|c|}{ High Volatility } \\
\hline & \multicolumn{2}{|c|}{ Simple Model } & \multicolumn{2}{|c|}{ Complex Model } & \multicolumn{2}{|c|}{ Simple Model } & \multicolumn{2}{|c|}{ Complex Model } \\
\hline & $\begin{array}{l}\text { Absolute } \\
\text { Fail }\end{array}$ & $\begin{array}{c}\text { Relative } \\
\text { Fail }\end{array}$ & $\begin{array}{l}\text { Absolute } \\
\text { Fail }\end{array}$ & $\begin{array}{l}\text { Relative } \\
\text { Fail }\end{array}$ & $\begin{array}{l}\text { Absolute } \\
\text { Fail }\end{array}$ & $\begin{array}{c}\text { Relative } \\
\text { Fail }\end{array}$ & $\begin{array}{l}\text { Absolute } \\
\text { Fail }\end{array}$ & $\begin{array}{c}\text { Relative } \\
\text { Fail }\end{array}$ \\
\hline Contributions & 69 & 285 & 72 & 197 & 258 & 440 & 279 & 310 \\
\hline Benefits & 563 & 609 & 544 & 543 & 682 & 655 & 675 & 588 \\
\hline Both & 680 & 563 & 653 & 491 & 789 & 640 & 771 & 560 \\
\hline
\end{tabular}

contributions or lower benefits during periods of "unrecognised gains". These challenges give rise to the quandary that having flexibility in the system reduces the chance of failure, but that the decision regarding contribution and benefit levels is a difficult one and open to manipulation.

We also note that the contribution lever is far less effective than the benefits lever for reducing failure scores. Indeed, if a retirement system is unable to adjust benefits, especially within the period of retirement, then the likelihood of failure is increased significantly. This conclusion is evident in all forms of the outputs produced, including the various sensitivities shown in the Appendix. The difference is so marked that we believe it is a vital learning point from designers and regulators of retirement vehicles.

\subsection{Secondary levers}

Secondary levers are those control mechanisms that can be adjusted, but are not directly linked to the primary levers of contributions and benefits.

\subsubsection{Inflation-linked versus non-inflation-linked benefits}

Retaining some discretion regarding the inflation-linkage of benefits reduces the probability of failure even against an inflation-linked contribution and benefits test. This conclusion is a specific subset of the conclusion regarding flexibility of adjusting benefits. In essence, the greater the freedom afforded to stakeholders regarding the flexibility of adjusting benefits and contributions, the greater the chance of avoiding failure.

Whilst this is a specific case of adjusting a primary lever, we note that it has political, legal and social significance. The political significance arises from historic practice in the United Kingdom regarding the compulsory indexation of pensions. The legal significance stems from the definition of accrued rights under international law. The social significance is present from the greater willingness to accept an absence of an increase rather than having a benefit taken away.

\subsubsection{Best estimate versus prudent funding}

One of the issues tested is whether or not a prudent approach to funding reduces the risk of failure. We observe that adjusting contributions and benefits is a far more significant factor than the decision regarding approach to funding.

We also note, however, that an overly pessimistic view of the likely expected outcome of the retirement system would, in all likelihood, increase the chance of failure and reduce transparency. 
In particular, it is of concern that stakeholder decisions are often made on a prudent basis, whereas the likelihood of expected future outcome is, by definition, on a best estimate basis. This problem is exacerbated where, as is usually the case, cross-generational subsidies arise.

Indeed, all collective solutions are likely at some point during their lifetime to experience the challenge of how wealth is distributed and this challenge is increasingly problematic where prudent assessments of outcomes are presented.

\subsubsection{Collective versus individual approaches}

The results show that the collective versus individual element of retirement vehicle structure makes no significant difference to the prospect of scheme failure. The small exception to this is in the very last few years of the run off stage when individual schemes fare better.

This conclusion is problematic for those who advocate collective vehicles as a means of sharing risk. The conclusion that collective vehicles are unlikely to significantly reduce the risk of failure should not be confused with the assertion that collective vehicles do not reduce risks for individuals. It is more that the overwhelming influences of contribution rates, benefit pay-outs, investment returns and economic conditions have by far a greater influence regarding whether or not a retirement vehicle is likely to fail.

\subsubsection{Volatility}

Whilst not a lever, other than indirectly through investment decisions, it is clear that higher volatility environments are more likely to lead to failure than normal volatility environments. Given the historic pattern of low volatility environments being followed by high volatility environments, this is particularly problematic. Indeed research regarding regime switching models would be informative on this point.

\subsection{Other levers}

In addition to the impact of primary and secondary levers, a number of other aspects of retirement system design have been tested. The inputs and parameters to these results are detailed in the Appendix together with a full set of results from which a number of observations can be made about relative decisions that are optimal in different circumstances. We set out our main conclusions below.

\subsubsection{Regularity of assessments}

One of the key features of the retirement vehicle is how often the appropriate levels of contributions and benefits are assessed. In particular, where a decision is required regarding adjustments, then the regularity of assessment influences the likelihood of failure.

Stakeholders could seek to adjust the relevant contribution or benefit levels more regularly with the intention of acting before an excessive surplus or deficit is created. Alternatively, they could adjust less frequently to avoid over-reacting to short-term volatility through over-adjustment.

For this particular part of the analysis, we are aware that our assumption regarding mean reversion within the model has a key influence. Whilst market conditions are volatile over the course of the lifetime of the scheme they will tend to produce average returns in line with our assumptions. 
This means that the extreme option of choosing to never adjust benefits or contributions is in effect a close proxy to that set out initially of a deterministic world.

This clearly would result in the lowest failure scores, because the retirement system would in effect be largely predictable. However, this only holds true if stakeholders have sufficient confidence in the predictability of investment markets. This poses two particular difficulties. First, there is a genuine risk that reversion of financial markets may not occur. Second, from a practical point of view, there is likely to be a legal requirement for regular assessments.

\subsubsection{Asymmetry of remediation}

Where the retirement system allows for the adjustment of contributions, we observe that adjusting less frequently with deficits has a much greater impact than for surpluses. This conclusion is largely drawn from the fact that failure only occurs in deficit scenarios. The contributions and benefits tests outlined earlier relate to excessive contribution requirements or inadequate benefit outcomes.

\subsubsection{Impact of lifecycle}

Remediation approaches taken pre-retirement are far more significant than post-retirement. This is evident across the entire range of retirement vehicles and largely stems from the greater certainty of eventual outcome in the post-retirement phase of the retirement vehicle.

\subsubsection{Acceptable fluctuation buffers}

Where primary levers are adjusted to reflect favourable or adverse experience, it is reasonable to apply a buffer within which no action is taken. When using best estimate assumptions, the size of the buffer has little impact on the likelihood of failure. This is largely because failure only occurs in those situations where there is significant adverse experience. In those cases the significant variations are greater than the buffer in place, so the buffer does not help prevent failure. The buffer may, however, increase the attractiveness of a retirement vehicle by providing some degree of stability.

Interestingly, when using prudent assumptions, a buffer can help reduce failure scores by eliminating those failures that arise from prudence alone, where the retirement system would otherwise be expected to restore back to full funding if allowed to do so.

\subsubsection{Ability to accept variable benefit streams}

The capacity of individuals to absorb risk is not equal for all individuals. As such, scaling the likelihood of failure fails to address the different risk sensitivities for the population as a whole. The influence of certain retirement vehicle design features increases with the risk that individuals are able to tolerate. In particular, there are two features that are significant, namely the inflation linkage of benefits and situations where only the benefits primary lever is used.

For individuals with low levels of risk tolerance, there is no significant difference in likely sustainability from including or excluding these levers. As a result, the design of vehicles for these members should be less driven by failure score considerations and instead focussed on social need. 


\section{Desirable Social Features of a Sustainable UK Retirement System}

Given the analysis and conclusions so far, it is appropriate to outline the desirable features of a UK retirement vehicle. Under all retirement vehicles, trade-offs exist at numerous levels.

\subsection{Cross-generational subsidies}

The smoothing of retirement income from generation to generation can occur wherever smoothing exists. For example, under the traditional UK defined benefit pension scheme, scheme deficits or surpluses are allowed to emerge, which are then either paid for or used to subsidise payments in future generations.

In the United Kingdom this is exacerbated by two key factors, namely the increasingly prudent approach to funding (including historical benefits), and the hardening of the pension promise.

This rising level of required prudence also increases the value placed on historical benefits and makes them appear a progressively more expensive option when compared to the contributions that were the "contract" employers thought they entered into, to back these benefits.

The hardening of the pension promise increases the real value of the benefit by increasing the benefit floor from the amount payable under the Minimum Funding Requirement regulations to the full pension paid in full (except in the event of employer insolvency).

\subsection{Relative wealth: how rich is my neighbour?}

One of the features of the satisfaction arising from wealth is that the feeling is relative. Individuals do not want to be a member of the only household on the street which does not have a car. Similarly, most individuals do not want to be a member of the only household on the street unable to afford a new car every 3 years, for example, even if this is not actually something they would otherwise aspire to (and therefore need or want income for).

\subsection{Desirable sustainable outcomes from investment of funds}

A vital consideration when assessing the sustainability of retirement vehicles is how they will be invested. The size of the assets available from the collective funded retirement vehicles market (including those currently in existence) is very large and significant compared with the size of the UK economy.

The investment of these funds could be either beneficial or destabilising for the UK economy. As a strong economy is beneficial to the sustainability of these vehicles (even if only as it increases the chance that sponsors will still be around to fund these schemes) it is vitally important that there are no perverse incentives or disincentives for investing these funds in ways that are inconsistent with the wider economic markets stability.

\subsection{Investment in the growth economy}

The assertion that individuals will be required to set aside assets for retirement is closely followed by the question of where those assets should be invested. The cumulative value of assets earmarked for retirement comfortably exceeds $£ 1$ tn in the United Kingdom. This is a significant investment. 
The challenge remains that individuals feel the need to reduce risk, because they are not able to absorb risk. Whilst a certain level of risk is inherent in all financial decisions there reaches a point for all individuals where this risk becomes too high to allow them to make the required life decisions. For example, if there is so much volatility with the level of known income that there is effectively no guarantee, then an individual will restrict any decisions to the very short term.

Poor investment returns in the few years leading to retirement can delay or even cancel an individual's retirement plans. This argument also applies through small groupings, such as defined benefit schemes, where the individual sponsors and trustees of these schemes find the risk unpalatable within the context of the situation in which they find themselves. Indeed, the influence of the UK Pensions Regulator is to drive de-risking in an attempt to secure the benefits already awarded to individuals.

The encouragement to invest assets in lower risk options encourages investment in (generally the United Kingdom) Government through bonds. By contrast, riskier investment encourages investment in (mostly United Kingdom) companies. There are degrees of riskiness and other investments, which encompass various sub-categories of government and company investment, but the central theme remains that low risk and return investments involve investment in the UK Government, whereas higher risk and return investments involve investment in UK companies.

By contrast, UK company investment increases the value of UK companies and, in turn, leads to a successful economy. The investment in growth assets is also expected to yield higher returns over the long-term and expected to yield higher benefits for the investor. A retirement system should allow individuals to invest in the growth economy for longer for both the benefit of the individual, but also the benefit to the economy.

\subsection{UK Government investment}

Investment in the UK Government is undesirable for two reasons. First, the UK Government does not currently want the investment. Indeed, it is striving to drive down its own debt. Second, the UK Government is not necessarily best placed to make UK investment decisions. Typically, Governments invest in infrastructure, whereas companies invest in exploiting that infrastructure.

Infrastructure is an illiquid investment that is expected to provide real returns similar to other growth asset classes, but less risky over the longer term. The reason these investments can prove unpopular is because they tend to be quite lumpy - they are large single undiversified investments, which are inappropriate for the single individual. When spread across many individuals, the overall risk-return profile would be ideal for pension fund investors, but when taken as a single investment, they are wholly inappropriate.

Pooled infrastructure investments allow pension fund investors to invest in the infrastructure asset class and provide a much-needed source of investment for major infrastructure projects.

\subsection{Regulation}

The role of regulation is problematic. Regulation naturally leads to broad standards, which may or may not be in the interests of the individuals that the regulations are seeking to protect. For example, the desire for de-risking in defined benefit schemes has sought to protect those individuals, but has encouraged the closure of the defined benefit structure for others. 
By its nature, pensions regulation is also subject the risk of "capture", namely when regulation is formed by those being regulated. This leads to a regulation system that is insular and may not reflect the political or social needs of the current society.

\subsection{Individual engagement}

We believe that the concept of "guaranteed" outcomes is unhelpful, in particular if they actually result in retirement benefit schemes having binary outcomes - members either receive the guaranteed amount or nothing in the event the vehicle fails. A more robust structure has a much lower probability of completely breaking, even if this removes the feeling of a "guarantee to members".

We also note that even the idea that a guarantee is able to provide members with certainty can be challenged. The focus on this to date has been mostly around ensuring members know exactly what they will receive in retirement. We believe that this is flawed for two reasons.

First, there are many other unknowns in the world, for example, the level of income tax that the government will impose at the time the retirement benefit is claimed by the individual. Second, if the provision of guarantees jeopardises the overall stability of the retirement system, then the guarantee is not worth the risk. This is because whilst some individuals might achieve good outcomes from the guarantee when the guarantee bites, it is likely that such conditions will cause providers and sponsors to opt out of supporting the system in the future, which in turn does not encourage the long-term individual and sponsor engagement that these vehicles require to be sustainable.

It is important that individuals engage with this process, but we believe a vital area of secondary research should be around the optimal approach of educating individuals. This area is explored further in paper authored by the Institute and Faculty of Actuaries defined ambition working party (Boulding et al, 2014).

\subsection{The case for sustainability}

By definition, retirement systems are long-term and need to stand the test of time, both for the system itself to provide good outcomes, but also so that trust in the system can be established. This is reflected in the UK government's rationale for its changes to the UK pensions' landscape. In particular, there are three examples that aim to achieve this objective.

First, UK auto-enrolment has not been made mandatory in order for it to remain sustainable. Individuals would have viewed the compulsory contributions as an additional tax, which would have been more subject to political interference at future elections.

Second, the flat rate state pension has been set at a level that is not too high and not too low in order to try to avoid the need for future tinkering.

Third, flexibilities announced as part of the 2014 Budget were, in part, driven by a concern that autoenrolment members would be forced to purchase a seemingly poor-value annuity at retirement, which would de-stabilise the auto-enrolment system.

Initial experience with auto-enrolment suggests that there is inertia in decision making around retirement choices. This is also evident in the acceptance of default funds for the majority of 
individuals in defined contribution schemes. Individuals tend to stick with the status quo unless the outcome is clearly broken.

\subsection{Engagement}

For a sustainable retirement system to exist in the workplace employer engagement is crucial. Sustainable and capital-efficient retirement systems are likely to be the most attractive to employers.

Whilst we have not specifically analysed historical experience, it is clear that most attempts at retirement systems have failed at some point, except where a significant pool of assets is available to underwrite the retirement system (e.g. the use of sovereign funds in Norway).

We have, therefore, focussed on sustainability for the following three reasons.

First, we believe that individual engagement is critical. Without this engagement, then the system is unappreciated and, therefore, less likely to be support by all stakeholders. Individual engagement follows from trust and certainty, which in turn follows from sustainability.

Second, to encourage employer engagement, a retirement vehicle must provide value for money so that the retirement benefit system is appreciated by individuals within acceptable cost parameters.

Third, sustainability follows from the absence of State interference. We observe that a sustainable retirement system that does not require State interference would be desirable to the State, but that it will always have a tendency to interfere for political reasons. By highlighting what it is that makes a retirement system sustainable, they will hopefully be discouraged from tinkering at things that will fundamentally break the system for easy wins.

\subsection{Final word}

Having considered the factors that influence the sustainability of retirement vehicles, we observe that the risk of failure is considerable. Indeed, in many cases failure is often more likely than not. Any retirement vehicle should be built to minimise the chance of failure. Increasing sustainability maximises confidence and has positive societal benefits.

At the same time, however, we note that even a well-designed retirement vehicle has a high chance of failure. As such, we recommend that all retirement vehicle designs plan for the outcome they strive to avoid - the day they fail.

\section{References}

The Association of Consulting Actuaries (2013). The unfinished agenda: growing workplace pensions fit for purpose, available at http://www.aca.org.uk/files/ACA_2013_survey_report_-_the_ unfinished_agenda-7_November_2013-20131107102735.pdf (accessed 21 June 2016).

Barr, N. \& Diamond, P. (2006). The economics of pensions. Oxford Review of Economic Policy, 22, 15-39.

Boulding, A., Edmondson, J., Foroughi, G., Graham, S., Page, T. \& Ritchie, A. (2014). Outcomes and defined ambition, The Defined Ambition Working Party, The Institute and Faculty of Actuaries, available at https://www.actuaries.org.uk/documents/outcomes-and-defined-ambition (accessed 21 June 2016). 
Byrne, A., Blake, D.P., Cairns, A.J.G. \& Dowd, K. (2007). Default funds in UK definedcontribution plans. Financial Analysts Journal, 63, 40-51.

Clacher, I. \& Draper, P. (2015). Pensions funds, in Wiley Encyclopaedia of Management, No. 4, pp. 1-10, John Wiley \& Sons, New Jersey (accessed 21 June 2016).

Department for Work and Pensions (2012). Reinvigorating Workplace Pensions, London, available at www.dwp.gov.uk/reinvigorating-workplace-pensions (accessed 21 June 2016).

Institute for Fiscal Studies. (2010). A history of state pensions in the UK: 1948 to 2010 available at www.ifs.org.uk/bns/bn105.pdf

Keynes, J.M. (1936). The General Theory of Employment, Interest and Money. London: Palgrave Macmillan.

Table 23 UK House Price Index, Office for National Statistics, https://www.ons.gov.uk/economy/ inflationandpriceindices/datasets/housepriceindexannualtables2039 (accessed 21 June 2016).

\section{Appendix A: The Economic Scenario Generator}

The economic scenario generator is a simple form auto-regressive model that models inflation and invested assets.

There are four variables required for the projections model:

- Inflation experience over the preceding year (Iet)

- Long-term inflation assumption (Ilt)

- Asset experience over the preceding year (Aet)

- Long-term asset assumption $(A l t)$

Simple model

These four variables have been modelled as follows:

- $I e t=N O R M I N V(R A N D(), I \mu, I \sigma)$

- $I l t=N O R M I N V(R A N D(), I \mu, I \sigma)$

- Aet $=\operatorname{NORMINV(RAND(),A\mu ,A\sigma )}$

- $A l t=\operatorname{NORMINV(RAND(),A\mu ,A\sigma )}$

These use the following parameters, parameter values shown earlier in the paper:

- $I \mu=$ Inflation long-term mean

- $I \sigma=$ Inflation standard deviation

- $A \mu=$ Asset return long term mean

- $A \sigma=$ Asset return standard deviation

\section{Correlated and mean reverting model set up}

These four variables have been modelled as follows:

- $I$ et $=$ Iet $-1+N O R M I N V(R A N D(), 0, I \mu)$

- $I l t=(I \mu-I l t-1) \times I \alpha+I V t-1 \times I \sigma+I l t-1$ 
- Aet $=$ Aet $-1 \times((1+A l t) /(1+A l t-1))^{\wedge} 10-1+\operatorname{NORMINV}(\operatorname{RAND}(), 0,1) \times A \beta$

- $A l t=(A \mu-A l t-1) \times A \alpha+A V t \times A \sigma+A l t-1$

These use the following parameters, parameter values shown earlier in the paper:

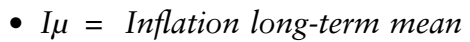

- I $\sigma=$ Inflation standard deviation

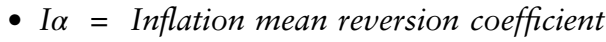

- $I V t=$ Inflation weiner process variable $=\operatorname{NORMINV}(\operatorname{RAND}(), 0,1)+I V t-1$

- $A \mu=$ Asset return long-term mean

- $A \sigma=$ Asset return standard deviation

- $A \alpha=$ Asset return mean reversion coefficient

- $A \beta=$ Asset experience variation coefficient

- $A V t=$ Asset return weiner process variable $=\operatorname{NORMINV}(\operatorname{RAND}(), 0,1)+A V t-1$

\section{Appendix B: Outputs}

\section{Inflation-linked benefits}

Non-inflation-linked benefits

Table 10. Assuming Both Absolute and Relative Failure in 1 Year Counts as Two Fails

\begin{tabular}{|c|c|c|c|c|c|c|c|c|}
\hline & \multicolumn{2}{|c|}{ Simple Normal } & \multicolumn{2}{|c|}{ Normal } & \multicolumn{2}{|c|}{ Simple High } & \multicolumn{2}{|c|}{ High } \\
\hline & $\begin{array}{c}\text { Absolute } \\
\text { Fail }\end{array}$ & $\begin{array}{c}\text { Relative } \\
\text { Fail }\end{array}$ & $\begin{array}{c}\text { Absolute } \\
\text { Fail }\end{array}$ & $\begin{array}{c}\text { Relative } \\
\text { Fail }\end{array}$ & $\begin{array}{c}\text { Absolute } \\
\text { Fail }\end{array}$ & $\begin{array}{c}\text { Relative } \\
\text { Fail }\end{array}$ & $\begin{array}{c}\text { Absolute } \\
\text { Fail }\end{array}$ & $\begin{array}{c}\text { Relative } \\
\text { Fail }\end{array}$ \\
\hline \multicolumn{9}{|l|}{ Collective } \\
\hline \multicolumn{9}{|l|}{ Prudent } \\
\hline Benefits & 69 & 285 & 72 & 197 & 258 & 440 & 279 & 310 \\
\hline Contributions & 563 & 609 & 544 & 543 & 682 & 655 & 675 & 588 \\
\hline Both & 680 & 563 & 653 & 491 & 789 & 640 & 771 & 560 \\
\hline \multicolumn{9}{|l|}{ Best estimate } \\
\hline Benefits & 129 & 307 & 126 & 197 & 298 & 454 & 307 & 315 \\
\hline Contributions & 646 & 579 & 570 & 472 & 732 & 640 & 683 & 541 \\
\hline Both & 738 & 553 & 653 & 439 & 824 & 635 & 764 & 522 \\
\hline \multicolumn{9}{|l|}{ Individual } \\
\hline \multicolumn{9}{|l|}{ Prudent } \\
\hline Benefits & 81 & 293 & 84 & 193 & 283 & 452 & 290 & 306 \\
\hline Contributions & 555 & 608 & 509 & 537 & 690 & 648 & 658 & 573 \\
\hline Both & 662 & 532 & 611 & 460 & 788 & 590 & 749 & 513 \\
\hline \multicolumn{9}{|l|}{ Best estimate } \\
\hline Benefits & 134 & 332 & 131 & 194 & 320 & 468 & 320 & 311 \\
\hline Contributions & 647 & 563 & 537 & 432 & 743 & 620 & 663 & 512 \\
\hline Both & 730 & 516 & 615 & 384 & 824 & 579 & 738 & 468 \\
\hline
\end{tabular}


Table 11. Assuming Both Absolute and Relative Failure in 1 Year Counts as One Fail

\begin{tabular}{|c|c|c|c|c|c|c|c|c|}
\hline & \multicolumn{2}{|c|}{ Simple Normal } & \multicolumn{2}{|c|}{ Normal } & \multicolumn{2}{|c|}{ Simple High } & \multicolumn{2}{|c|}{ High } \\
\hline & $\begin{array}{c}\text { Absolute } \\
\text { Fail }\end{array}$ & $\begin{array}{c}\text { Relative } \\
\text { Fail }\end{array}$ & $\begin{array}{c}\text { Absolute } \\
\text { Fail }\end{array}$ & $\begin{array}{c}\text { Relative } \\
\text { Fail }\end{array}$ & $\begin{array}{c}\text { Absolute } \\
\text { Fail }\end{array}$ & $\begin{array}{c}\text { Relative } \\
\text { Fail }\end{array}$ & $\begin{array}{c}\text { Absolute } \\
\text { Fail }\end{array}$ & $\begin{array}{c}\text { Relative } \\
\text { Fail }\end{array}$ \\
\hline \multicolumn{9}{|l|}{ Collective } \\
\hline \multicolumn{9}{|l|}{ Prudent } \\
\hline Benefits & 69 & 279 & 72 & 191 & 258 & 392 & 279 & 270 \\
\hline Contributions & 563 & 260 & 544 & 256 & 682 & 227 & 675 & 227 \\
\hline Both & 680 & 141 & 653 & 140 & 789 & 143 & 771 & 141 \\
\hline \multicolumn{9}{|l|}{ Best estimate } \\
\hline Benefits & 129 & 296 & 126 & 186 & 298 & 402 & 307 & 271 \\
\hline Contributions & 646 & 203 & 570 & 196 & 732 & 191 & 683 & 192 \\
\hline Both & 738 & 120 & 653 & 113 & 824 & 127 & 764 & 123 \\
\hline \multicolumn{9}{|l|}{ Individual } \\
\hline \multicolumn{9}{|l|}{ Prudent } \\
\hline Benefits & 81 & 284 & 84 & 184 & 283 & 395 & 290 & 259 \\
\hline Contributions & 555 & 272 & 509 & 274 & 690 & 232 & 658 & 239 \\
\hline Both & 662 & 144 & 611 & 148 & 788 & 125 & 749 & 134 \\
\hline \multicolumn{9}{|l|}{ Best estimate } \\
\hline Benefits & 134 & 316 & 131 & 178 & 320 & 406 & 320 & 258 \\
\hline Contributions & 647 & 200 & 537 & 188 & 743 & 187 & 663 & 194 \\
\hline Both & 730 & 115 & 615 & 105 & 824 & 105 & 738 & 114 \\
\hline
\end{tabular}

Table 12. Assuming Both Absolute and Relative Failure in 1 Year Counts as Two Fails

\begin{tabular}{|c|c|c|c|c|c|c|c|c|}
\hline & \multicolumn{2}{|c|}{ Simple Normal } & \multicolumn{2}{|c|}{ Normal } & \multicolumn{2}{|c|}{ Simple High } & \multicolumn{2}{|c|}{ High } \\
\hline & $\begin{array}{c}\text { Absolute } \\
\text { Fail }\end{array}$ & $\begin{array}{c}\text { Relative } \\
\text { Fail }\end{array}$ & $\begin{array}{c}\text { Absolute } \\
\text { Fail }\end{array}$ & $\begin{array}{c}\text { Relative } \\
\text { Fail }\end{array}$ & $\begin{array}{c}\text { Absolute } \\
\text { Fail }\end{array}$ & $\begin{array}{c}\text { Relative } \\
\text { Fail }\end{array}$ & $\begin{array}{c}\text { Absolute } \\
\text { Fail }\end{array}$ & $\begin{array}{c}\text { Relative } \\
\text { Fail }\end{array}$ \\
\hline \multicolumn{9}{|l|}{ Collective } \\
\hline \multicolumn{9}{|l|}{ Prudent } \\
\hline Benefits & 30 & 258 & 33 & 208 & 181 & 413 & 201 & 323 \\
\hline Contributions & 482 & 582 & 467 & 534 & 630 & 633 & 624 & 583 \\
\hline Both & 619 & 536 & 600 & 488 & 753 & 617 & 740 & 563 \\
\hline \multicolumn{9}{|l|}{ Best estimate } \\
\hline Benefits & 68 & 288 & 73 & 209 & 217 & 439 & 232 & 325 \\
\hline Contributions & 551 & 548 & 481 & 457 & 676 & 617 & 623 & 530 \\
\hline Both & 664 & 522 & 590 & 428 & 781 & 612 & 722 & 519 \\
\hline \multicolumn{9}{|l|}{ Individual } \\
\hline \multicolumn{9}{|l|}{ Prudent } \\
\hline Benefits & 40 & 253 & 44 & 194 & 205 & 423 & 221 & 311 \\
\hline Contributions & 468 & 585 & 429 & 533 & 637 & 629 & 607 & 570 \\
\hline Both & 582 & 500 & 541 & 448 & 741 & 566 & 708 & 507 \\
\hline \multicolumn{9}{|l|}{ Best estimate } \\
\hline Benefits & 84 & 300 & 85 & 196 & 244 & 452 & 261 & 314 \\
\hline Contributions & 557 & 537 & 456 & 421 & 692 & 599 & 611 & 503 \\
\hline Both & 652 & 483 & 548 & 366 & 780 & 554 & 696 & 457 \\
\hline
\end{tabular}


Table 13. Assuming Both Absolute and Relative Failure in 1 Year Counts as One Fail

\begin{tabular}{|c|c|c|c|c|c|c|c|c|}
\hline & \multicolumn{2}{|c|}{ Simple Normal } & \multicolumn{2}{|c|}{ Normal } & \multicolumn{2}{|c|}{ Simple High } & \multicolumn{2}{|c|}{ High } \\
\hline & $\begin{array}{c}\text { Absolute } \\
\text { Fail }\end{array}$ & $\begin{array}{c}\text { Relative } \\
\text { Fail }\end{array}$ & $\begin{array}{c}\text { Absolute } \\
\text { Fail }\end{array}$ & $\begin{array}{c}\text { Relative } \\
\text { Fail }\end{array}$ & $\begin{array}{c}\text { Absolute } \\
\text { Fail }\end{array}$ & $\begin{array}{c}\text { Relative } \\
\text { Fail }\end{array}$ & $\begin{array}{c}\text { Absolute } \\
\text { Fail }\end{array}$ & $\begin{array}{c}\text { Relative } \\
\text { Fail }\end{array}$ \\
\hline \multicolumn{9}{|l|}{ Collective } \\
\hline \multicolumn{9}{|l|}{ Prudent } \\
\hline Benefits & 30 & 254 & 33 & 204 & 181 & 379 & 201 & 288 \\
\hline Contributions & 482 & 285 & 467 & 280 & 630 & 245 & 624 & 243 \\
\hline Both & 619 & 159 & 600 & 155 & 753 & 153 & 740 & 152 \\
\hline \multicolumn{9}{|l|}{ Best estimate } \\
\hline Benefits & 68 & 280 & 73 & 200 & 217 & 398 & 232 & 284 \\
\hline Contributions & 551 & 229 & 481 & 218 & 676 & 208 & 623 & 205 \\
\hline Both & 664 & 137 & 590 & 125 & 781 & 137 & 722 & 133 \\
\hline \multicolumn{9}{|l|}{ Individual } \\
\hline \multicolumn{9}{|l|}{ Prudent } \\
\hline Benefits & 40 & 248 & 44 & 189 & 205 & 382 & 221 & 271 \\
\hline Contributions & 468 & 303 & 429 & 303 & 637 & 253 & 607 & 256 \\
\hline Both & 582 & 162 & 541 & 163 & 741 & 138 & 708 & 143 \\
\hline \multicolumn{9}{|l|}{ Best estimate } \\
\hline Benefits & 84 & 289 & 85 & 184 & 244 & 403 & 261 & 266 \\
\hline Contributions & 557 & 226 & 456 & 211 & 692 & 203 & 611 & 207 \\
\hline Both & 652 & 128 & 548 & 113 & 780 & 114 & 696 & 120 \\
\hline
\end{tabular}

